\title{
Management of atopic dermatitis: safety and efficacy of phototherapy
}

This article was published in the following Dove Press journal:

Clinical, Cosmetic and Investigational Dermatology

5 October 2015

Number of times this article has been viewed

\author{
Annalisa Patrizi \\ Beatrice Raone \\ Giulia Maria Ravaioli \\ Department of Specialized, Diagnostic \\ and Experimental Medicine, Division \\ of Dermatology, University of \\ Bologna, Bologna, Italy
}

Abstract: Atopic dermatitis (AD) is a common chronic inflammatory skin disease that can affect all age groups. It is characterized by a relapsing course and a dramatic impact on quality of life for patients. Environmental interventions together with topical devices represent the mainstay of treatment for $\mathrm{AD}$, in particular emollients, corticosteroids, and calcineurin inhibitors. Systemic treatments are reserved for severe cases. Phototherapy represents a valid second-line intervention in those cases where non-pharmacological and topical measures have failed. Different forms of light therapy are available, and have showed varying degrees of beneficial effect against $\mathrm{AD}$ : natural sunlight, narrowband (NB)-UVB, broadband (BB)-UVB, UVA, UVA1, cold-light UVA1, UVA and UVB (UVAB), full-spectrum light (including UVA, infrared and visible light), saltwater bath plus UVB (balneophototherapy), Goeckerman therapy (coal tar plus UVB radiation), psoralen plus UVA (PUVA), and other forms of phototherapy. In particular, UVA1 and NB-UVB have gained importance in recent years. This review illustrates the main trials comparing the efficacy and safety of the different forms of phototherapy. No sufficiently large randomized controlled studies have been performed as yet, and no light modality has been defined as superior to all. Parameters and dosing protocols may vary, although clinicians mainly refer to the indications included in the American Academy of Dermatology psoriasis guidelines devised by Menter et al in 2010. The efficacy of phototherapy (considering all forms) in AD has been established in adults and children, as well as for acute (UVA1) and chronic (NB-UVB) cases. Its use is suggested with strength of recommendation B and level of evidence II. Home phototherapy can also be performed; this technique is recommended with strength $\mathrm{C}$ and level of evidence III. Phototherapy is generally considered to be safe and well tolerated, with a low but established percentage of short-term and long-term adverse effects, with the most common being photodamage, xerosis, erythema, actinic keratosis, sunburn, and tenderness. A carcinogenic risk related to UV radiation has not been excluded. Phototherapy also has some limitations related to costs, availability, and patient compliance. In conclusion, phototherapy is an optimal second-line treatment for AD. It can be used as monotherapy or in combination with systemic drugs, in particular corticosteroids. It must be performed conscientiously, especially in children, and must take into account the patient's features and overall condition.

Keywords: atopic eczema, atopic dermatitis, phototherapy, NB-UVB, UVA1, balneophototherapy, PUVA

\section{Introduction}

Atopic dermatitis (AD), also known as atopic eczema, is a common inflammatory skin disease characterized by a chronic and relapsing course. It affects patients of all ages, although it is more common in children. It is clinically identified by eczematous and pruritic lesions, which can cause dramatic deterioration in quality of life for patients 
and their families. AD is a major medical and socioeconomic issue because of its high incidence, which has been increasing rapidly in recent decades. ${ }^{1}$ The disease is often associated with other forms of atopy, including asthma, food allergies, and rhinitis, and is commonly associated with high serum immunoglobulin E levels.

Although the pathogenesis of AD is still debated, several studies have documented the primary role of a defective epidermal barrier function in promotion of the disease, together with marked epidermal hyperplasia and predominantly Th2/22 immune activation, which can switch toward Th1 in the chronic stages. ${ }^{2-8}$

Treatment for AD consists mainly of non-pharmacological interventions, initially avoidance of trigger factors, together with topical therapies like emollient and moisturizers, corticosteroids, and calcineurin inhibitors. In particular, use of emollients is well tolerated and mainly aimed at restoring or replacing the intrinsic and/or externally induced abnormalities of the skin. ${ }^{9}$ The class of moisturizers and emollients includes products with different degrees of viscosity, including oil-in-water emulsions, ointments, creams, and preparations that are rich in water. The most commonly used conventional products are Vaseline or paraffin oil, lanolin, fatty acids, and fatty alcohols, together with hydrophilic polymers rich in glycosaminoglycans, collagen, and gelling polysaccharides. Several innovative devices have also been developed in recent years. These are mainly epidermal barrier restorers, obtained with physiological lipids (ceramides, cholesterol, omega-3, or omega-6 polyunsaturated fatty acids). Examples include nanoparticles, liposomes, the 3:1:1 ceramide-dominant formula, and the BioMimic ${ }^{\circledR}$ and Lipigenium $^{\circledR}$ formulas. Despite its relapsing nature, AD is usually well controlled by these first-line interventions. Systemic corticosteroids and other anti-inflammatory treatments are usually reserved for severe cases. ${ }^{10,11}$

Light therapy has enormous therapeutic potential for patients whose daily personal and social life is dramatically affected by AD. Phototherapy must be integrated in a comprehensive treatment plan, together with a complete evaluation of disease severity and patient compliance. In particular, its use can be central in both chronic and acute AD in children and adults as a second-line intervention after failure of environmental and topical measures. ${ }^{12}$ According to the patient's condition and preferences, it represents an additional option to third-generation emollients and other innovative sources, which represent the baseline treatment.

Use of phototherapy in AD was mainly empirical during the last century, and only few randomized controlled trials have been carried out in recent years to compare the different phototherapeutic regimens. Since the evidence of its effectiveness has not been systematically reviewed as yet, phototherapy must be performed carefully and supplemented by a global and comprehensive overview of the AD patient. ${ }^{13}$

\section{Phototherapy for atopic dermatitis}

The definition of phototherapy derives from the Greek "therapy with light" and refers to a therapeutic technique based on the beneficial effect of light waves on several pathological conditions. It is frequently used today as a treatment for dermatological diseases such as psoriasis, acne, and AD, as well as for sleep disorders and some psychiatric illnesses.

The use of phototherapy in dermatology began in the 1890s. Goeckerman first reported its medical application in 1925 for the treatment of severe or refractory psoriasis. ${ }^{14}$ At around the same time, in the early 1920s, sea air was observed to be beneficial for $\mathrm{AD}$, with several patients reporting significant improvement of the disease during the summer months. However, it was only in 1948 that Nexman documented the beneficial effect of exposing patients to UV radiation emitted by carbon arc lamps. ${ }^{15}$ Thirty years later, Morison et al published the report that led to phototherapy becoming a mainstay in the treatment of $\mathrm{AD}$, documenting that refractory $\mathrm{AD}$ could be treated successfully with oral psoralen and UV light. ${ }^{16}$

Since the 1970s, a number of types of lamps have been developed with varying UV emission spectra, each set to a specific light wavelength. Moreover, many phototherapeutic regimens have been developed for the treatment of $\mathrm{AD}$, and are often associated with systemic agents, ie, photochemotherapy.

Recent advances in molecular immunology and photobiology indicate that the efficacy of phototherapy is multifactorial. First, UV radiation targets inflammatory cells on the skin, inducing positive immunosuppressive effects by altering cytokine production, inducing apoptosis of infiltrating T-cells, and by inhibiting the antigen-presenting function of Langerhans cells. ${ }^{17-19}$ Moreover, UV radiation can protect the skin by inducing thickening of the stratum corneum which could limit eczematous reactions and prevent entry of external antigens. ${ }^{20}$ Finally, skin colonization by Staphylococcus aureus and Pityrosporum orbiculare may be prevented or reduced by the antibacterial effect of UV radiation. In particular, narrow-band (NB)-UVB radiation has been proved to reduce production of superantigens and alter mRNA levels of antimicrobial peptides. ${ }^{21-24}$

The different forms of light therapy have had varying degrees of beneficial effect in patients with AD. The light 
therapies available are numerous, and include natural sunlight, NB-UVB, broadband (BB)-UVB, UVA, UVA1, cold-light UVA1, UVA and UVB (UVAB), full-spectrum light (including UVA, infrared and visible light), saltwater bath plus UVB (balneophototherapy), Goeckerman therapy (coal tar plus UVB radiation), psoralen plus UVA (PUVA), and other forms of phototherapy. ${ }^{17,19,25-28}$ In particular, the use of UVA1 and NB-UVB has gained importance in recent years.

Moreover, other newer techniques and devices have emerged as potentially effective sources, eg, extracorporeal photopheresis, $308 \mathrm{~nm}$ monochromatic excimer light, and pulse-dye laser. ${ }^{13,21} \mathrm{~A}$ short description of the principal phototherapies is presented in the following sections.

\section{Broadband UVB}

Use of BB-UVB (280-315 nm) therapy in AD started with the study of Nexman in 1948,,$^{15}$ and its efficacy was largely confirmed during the 1980s and 1990s in the studies reported by Hannuksela et al and Jekler and Larkö, in which irradiation was derived from fluorescent and mercury arc lamps and, in particular, the Psorilux 9050 C.$^{20,29-32}$ This device was later replaced by an NB-UVB fluorescent lamp (Philips TL01) able to completely eliminate waves in the UVA range from the spectrum. ${ }^{13,33}$

\section{Narrowband UVB}

By excluding shortwave length UVB radiation, NB-UVB $(311-313 \mathrm{~nm})$ is much less erythemogenic than BB-UVB. ${ }^{13}$ Although this treatment seems to be associated with an increased risk of skin cancer, its efficacy is clearly superior to that of BB-UVB. Due to its high efficacy, application of NBUVB often achieves rapid clinical remission and overcomes the oncogenic risk as a result of reduced exposure. ${ }^{13} \mathrm{NB}-\mathrm{UVB}$ induces apoptosis of epidermal $\mathrm{T}$ lymphocytes by damaging DNA and activating death receptors. Moreover, it inhibits the release of cytokines and the Th1 response (which is typically hyperactivated in the chronic stages of $\mathrm{AD}$, whereas in the acute phase is typical in Th2-activation), leading to a Th2 switch. Due to its restricted wavelength, penetration of UVB radiation is confined to the epidermis. Since it does not reach the dermis, the effect of UVB phototherapy is superficial and best suited for chronic AD. ${ }^{13,23,24}$

\section{UVAB}

UVAB (280-400 nm) phototherapy has been used for AD since the early reports of its efficacy published by Jekler and Larkö. ${ }^{20,29}$ The wave length of both UVA and UVB radiation spectra can be emitted by a single device, for example, the Metec Helarium (C). Otherwise, they can be combined as two separate simultaneous or subsequent emissions; the latter technique allows the physician to administer the two doses of radiation separately. However, introduction of NB-UVB and UVA1 has resulted in less use of UVAB. ${ }^{13}$

\section{UVA and UVAI}

Due to the need for long exposure times to obtain effective doses, UVA (315-400 nm) therapies have never been firstchoice options for AD. This disadvantage was overcome by the introduction of UVA1 (340-400 nm) lamps, which are able to eliminate UVA2 radiation ( $320-340 \mathrm{~nm})$ and all of its adverse effects. UVA1 devices allow application of high doses that was not possible with UVA devices. UVA1 radiation acts differently to PUVA and UVB, in that it is able to avoid burning the skin while penetrating deep into the dermis and into the superficial blood vessel plexus. Here it has multiple biological effects, inducing apoptosis of T-cells and immature mast cells, increased collagen synthesis by matrix metalloproteinase-1, inhibition of calcineurin, and suppression of tumor necrosis factor alpha, interleukin-12, interferon-gamma, and intercellular adhesion molecule-1. ${ }^{13,34-40}$

The applications of UVA1 are broad and include a variety of situations. UVA1 was demonstrated to be effective in chronic $\mathrm{AD}$, particularly in acute flares, and can be administered in a high dose (HD, 80-130 J/ $\mathrm{cm}^{2}$ ), medium dose (MD, $\left.40-80 \mathrm{~J} / \mathrm{cm}^{2}\right)$, or low dose $\left(\mathrm{LD},<40 \mathrm{~J} \mathrm{~cm} /{ }^{2}\right) .{ }^{19,41}$ High doses of UVA1 may involve heat, making their use intolerable, which led to the development of cold-light UVA1 lamps that include a cooling system for filtering the infrared radiation. ${ }^{13}$ UVA1 treatment times can range from 10 minutes to 1 hour per session. Specific lamps emitting only UVA1 radiation are usually expensive and require specific cabins with unique space and dedicated ventilation machinery. UVA therapy is more accessible and less costly than UVA1. UVA emission includes $90 \%$ UVA1 radiation, so is an effective source when UVA1 systems are not available, allowing the patient to receive the beneficial effects of phototherapy. Since UVA radiation penetrates deep into the dermis, it is most appropriate for patients with acute AD. In particular, UVA radiation acts on the Langerhans cells of the skin, having an immunomodulatory effect. ${ }^{40,42}$

\section{Photochemotherapy (PUVA, balneophototherapy)}

The term PUVA refers to the combined administration of UVA and psoralens, eg, 8-methoxypsoralen and 8-MOP. 
Systemic PUVA is taken orally, and topical formulations include bath-PUVA (balneophototherapy) and cream-PUVA. Balneophototherapy can be used with UVA with or without UVB radiation; in the latter case, psoralens are often substituted by salt in water solution (photobrine therapy). Balneophototherapy can be synchronous or asynchronous. For example, bath-PUVA usually consists of immediate UVA exposure after 20-30 minutes of bathing in warm water containing $0.5-1.0 \mathrm{mg} / \mathrm{L}$ of a psoralen, whereas synchronous balneotherapy provides concomitant exposure to NB-UVB and salt water. In cream-PUVA, $0.0006 \%$ psoralencontaining oil-in-water ointment is applied to defined areas of skin 30-60 minutes before irradiation. ${ }^{13,43,44}$ Although beneficial effects of PUVA can be expected in psoriasis and AD, it must be borne in mind that PUVA should not be administered in the long term, since it can be carcinogenic. ${ }^{13,45}$ PUVA is thought to act by inducing photoadducts that inhibit cell proliferation, and at higher doses by leading T-cells to become necrotic and apoptotic. ${ }^{13,46-48}$ Tominaga et al recently reported that PUVA also relieves pruritus in AD by reducing epidermal hyperinnervation. ${ }^{49}$

\section{Recommendations and efficacy}

The efficacy of phototherapy (considering all forms) has strength of recommendation B and level of evidence II in the treatment of $\mathrm{AD} \cdot{ }^{12,16,20,25,50-60}$ Home phototherapy is recommended with strength $\mathrm{C}$ and level of evidence III. ${ }^{12,61}$ It is important to stress that phototherapy is a second-line treatment and should be reserved for cases where first-line therapies, including behavioral measures and topical devices, have failed or been ineffective. Phototherapy has some limitations, in that patients have to be compliant enough to undergo frequent treatment (usually 3-5 applications a week for a total of 2-3 months). Further, UV therapy must be administered by specialized staff and involves use of expensive technical equipment. ${ }^{13}$ Moreover, some body areas can be hairy or difficult to reach by radiation (eg, the head, genitals, and skin folds in the armpit or groin), and the efficacy of the treatment is less in these areas. For all these reasons, it is necessary to choose the appropriate light modality carefully, considering disease severity, the status of the patient, cost and availability, location of the lesions, phototype, any history of skin cancer, and photosensitizing anamnesis.

Home phototherapy may be considered as an option for patients in whom phototherapy cannot be used in conventional settings, but only when supervised and directed by an expert physician. To these conditions, efficacy and cost-effectiveness of 13 years of experience of a home ser- vice in the UK were established in the comprehensive review reported by Cameron et al. ${ }^{62}$

In general, phototherapy is considered to be an additional option to topical conventional or innovative treatments (moisturizers, emollients, calcineurin inhibitors, steroids), and its advantages are often related to the clinical presentation and disease severity.

Not enough randomized controlled trials of phototherapy have been done as yet. Furthermore, in a recent global systematic review of 905 patients by Garritsen et al, most of the trials included had small sample sizes, used varying dosing parameters and were limited in terms of comparability due to their qualitative and clinical heterogeneity. ${ }^{19}$ Therefore, no fully reliable and comprehensive meta-analysis of these studies could be performed. Moreover, no light modality has been defined as superior to the others.

Nevertheless, some conclusions can be drawn from past experience. Several studies report improvement of clinical scores and durable remissions in patients with $\mathrm{AD}$ as a result of use of phototherapy. These data establish the efficacy of phototherapy in $\mathrm{AD}$ and validate it as a good therapeutic option for both adults and children.

It has been documented that an artificial light source achieves better results than natural sunlight. ${ }^{25}$

UVB, in particular NB-UVB, is now commonly chosen as the best therapeutic option, due to its efficacy, availability, good tolerability, and low risk. ${ }^{12,31}$ The studies of Jekler and Larkö are mainstays of UVB phototherapy, in which the authors demonstrated the efficacy of 8 weeks of application of UVB on one-half of the body in 17 patients with AD when compared with visible light (applied on the other half of the body). The same authors later verified in a study of 24 patients that the efficacy of nearly erythemogenic UVB doses achieved beneficial results similar to those of $50 \%$ lower doses. ${ }^{20,29-31}$ Hannuksela et al verified good clinical results in $93 \%$ of 107 atopic patients treated with UVB. ${ }^{32}$ Larger studies performed in subsequent years confirmed the positive effect of UVB on AD.

With the advent of NB-UVB, more trials demonstrated the effectiveness of this new technique. For example, a $68 \%$ reduction of clinical $\mathrm{AD}$ severity score was verified by George et al in 21 patients with severe AD after 12 weeks of treatment three times weekly. ${ }^{63}$ Despite not being able to exclude the risk of carcinogenesis, NB-UVB was also tested in children, with satisfactory results. In particular, good remission rates were demonstrated by Jury et al ( $68 \%$ of 25 children treated with a median of 24 exposures) and by Clayton et al ( $40 \%$ of 50 children with severe AD treated with more than 
ten exposures) in their studies. ${ }^{53,59}$ In one recent trial, Tan et al validated the efficacy and tolerability of NB-UVB in 116 children aged under 16 years and affected by $\mathrm{AD}(\mathrm{n}=61)$ or other skin disease. After a mean of 32.4 treatments, $72 \%$ of the 116 children responded to therapy. ${ }^{64}$ Similarly, the effectiveness of 12 weeks of NV-UVB treatment in 26 children aged 3-16 years with moderate to severe AD was objectively demonstrated in a recent randomized controlled trial by Darnè et al. ${ }^{65}$ The authors used quantitative scores to measure symptoms and the extension of the disease. Both these parameters were found to be with differences of $55 \%$ and $25 \%$, respectively, compared with the control group, together with a significant improvement in quality of life. In 2011, Tintle et al carried out an innovative study, in which they matched the SCORAD (SCORing Atopic Dermatitis) evaluation with histopathological and molecular analysis of skin samples in 12 patients with moderate to severe AD treated with NBUVB (three times weekly for up to 12 weeks). The result was a $>50 \%$ improvement in the SCORAD for all patients, and also marked cytological and immune modification, ie, suppression of the Th2, T22, and Th1 pathways, and reversal of disease activity, ie, reduction of T-cells and cytokines, and normalization of cell differentiation, epidermal hyperplasia, and expression of barrier proteins. ${ }^{2}$

UVA1 has also emerged as one of the most effective forms of phototherapy for improving clinical symptoms. Its action was first documented in a pilot study, and it later showed significantly better results than UVAB, in addition to having a very rapid action (response within only six applications in all patients in the study reported by Krutmann et al). ${ }^{66-68}$ However, subsequent research reported controversial and less enthusiastic results, highlighting the limit of heat development using UVA1. ${ }^{69}$ Encouraging results came with the advent of cold-light UVA1: these devices included a cooling system to eliminate wavelengths $>530 \mathrm{~nm}$ and thereby decreased the heat load..$^{30,53,70}$ In a trial by von Kobyletzki et al that included 120 patients with severe $\mathrm{AD}$, this new technique was shown to dramatically reduce the SCORAD score and to be clinically more effective than UVAB and MD-UVA1 (treatments lasted 15 days, with 4 weeks of follow-up) ${ }^{68}$ High-dose UVA1 and medium-dose UVA1 showed similar results in most studies, which were confirmed by Tzaneva et al who applied MD-UVA1 and high-dose UVA1 on each half of the body and compared the outcomes after 2 weeks. ${ }^{71,72}$ This evidence suggests that, in clinical practice, medium doses should be preferred over high doses, to reduce negative effects and obtain better tolerability. LD-UVA1 was found not be efficient for treatment of AD. ${ }^{72}$ For moderate to severe
$\mathrm{AD}$, the common recommendation is to use MD-UVA1 with a course of 15 exposures. ${ }^{40}$

No significant differences in improvement of clinical scores emerged in subsequent trials comparing NB-UVB and UVA1 in patients with moderate to severe AD. ${ }^{18,42,73}$ Clinical practice suggests that MD-UVA1 is particularly useful for acute cases, while NB-UVB is optimal for chronic disease; however, both these treatment modalities are today considered first-choice options by clinicians. ${ }^{19,21,66,69,72}$

Second-choice modalities of phototherapy are PUVA (systemic PUVA and bath-PUVA or cream-PUVA) and balneophototherapy (in particular, balneotherapy associated with NB-UVB). ${ }^{48}$ These treatments have showed good clinical outcomes, comparable with those using NB-UVB and UVA1, but few relevant reliable studies are available. Moreover, rebound after termination of PUVA was reported in some cases. ${ }^{16,56,74-76}$ George et al reported a SCORAD reduction in $64 \%$ of cases by PUVA and in $66 \%$ of cases by NB-UVB (each type of radiation was applied to half of the body, three times weekly, in 12 patients with severe AD). ${ }^{63}$ The best results come from the randomized controlled trial reported by Heinlin et al in 2011. These authors compared the effects of synchronous balneotherapy (NB-UVB therapy and synchronous bathing in $10 \%$ dead sea salt solution) with conventional NB-UVB in 169 patients. At 6 months of follow-up, 35 treatment sessions of synchronous balneotherapy achieved a significantly better SCORAD improvement than that seen in the control group, with a difference of $26.2 \%{ }^{76}$

UVA and UVAB are other options, although they are more frequently associated with side effects than UVA1 and NBUVB. UVAB seems not to be chosen often today, given its limited efficacy and availability. However, UVAB was commonly used in the past because it gave better clinical results than UVA or BB-UVB. ${ }^{20,29}$ UVAB was also documented to be less effective than cyclosporin and corticosteroids, but on the other hand obtained less favorable results than high-dose UVA $1 .{ }^{19,66-68,77}$ However, a few studies have validated the use of UVAB in some cases; for example, in 2003, a significant reduction in SCORAD score was reported in $68.3 \%$ of a pediatric population with a variety of skin diseases $(n=21) .{ }^{78} \mathrm{In}$ one recent randomized controlled trial, UVA was documented to be less effective in 73 patients with moderate to severe AD than NB-UVB but better than BB-UVB, and similar to full-spectrum light $(320-5000 \mathrm{~nm}) .^{70}$

In view of their lesser efficacy, BB-UVB and fullspectrum light are rarely recommended for the treatment of AD. However, UVA lamps are widespread and more commonly available than specific UVA1 devices, and UVA 
radiation emits $90 \%$ of UVA1 wavelengths. For this reason, UVA still remains a good therapeutic option for AD. ${ }^{27,30}$ Last-choice treatments are the older forms of light therapy, eg, Goeckerman therapy and heliothalassotherapy, the role of which remains uncertain. ${ }^{19}$

\section{Dosage and therapeutic protocols}

The use of phototherapy for AD is mainly empirical and is based on clinical practice and evidence from a limited number of studies. In fact, as yet, no scheduling has been validated as most effective. The decision must be made balancing risks and benefits and considering multiple factors, including the type of patient, compliance, cost, availability, and ease of use. It is recommended to perform a careful physical examination and detailed anamnesis of the patient, evaluating in particular any use of photosensitizing medications. ${ }^{12}$

Parameters and dosing protocols may vary, although clinicians mainly refer to the indications included in the American Academy of Dermatology psoriasis guidelines published by Menter et al in 2010. ${ }^{50}$ These guidelines contain specific dosages for NB-UVB, BB-UVB, and UVA. The initial dose is related to the patient's skin surface $\left(\mathrm{mJ} / \mathrm{cm}^{2}\right)$ and is based on Fitzpatrick skin type (I-VI). Treatment is administered 3-5 times a week, usually for 4-8 weeks, with an increase in dosage after each treatment. Otherwise, the initial radiation and its increase can be determined according to the minimal erythema dose.

Phototherapy can be administered either intermittently or continuously as maintenance treatment. ${ }^{12,51}$ Moreover, it can be combined with topical therapies, such as emollients or corticosteroids. This may enhance the beneficial effect and also have a corticosteroid-sparing action and reduce the need of topical immunomodulators, as verified by numerous studies. However, caution is needed when using topical calcineurin inhibitors with light therapy. ${ }^{12,32,63,79,80}$

\section{Safety and adverse effects}

Phototherapy is generally considered to be safe and well tolerated. Most studies report a low percentage of noncompliance and adverse events in patients with AD. However, no exact incidence of side effects has been published as yet due to the lack of wide studies with lasting follow-up. ${ }^{25,31,51-53}$ However, a number of trials have reported on common short-term and long-term adverse effects related to the use of phototherapy in patients with psoriasis, which are now well known. Thus, the potential risks must be carefully considered when using phototherapy in patients with AD. The more common risks include photodamage, xerosis, erythema, actinic keratosis, sunburn, and tenderness. Less frequently, phototherapy induces lentigines, folliculitis (UVA1, PUVA), polymorphous skin eruption and other photosensitive reactions, photo-onycholysis (PUVA), hypertrichosis, pruritus (UVA1), reactivation of herpes simplex virus (UVA1), hyperpigmentation, redness (UVA1), cataract (UVA), and signs of systemic toxicity (PUVA).

Most side effects can explained by the physiological degree of skin penetration of different radiations: in particular, UVB mainly causes erythema and other epidermal adverse reactions, while the action of UVA is less erythemogenic, but reaches the dermis causing photodamage. ${ }^{40}$ Most feared and less clear long-term consequences of phototherapy are its carcinogenic effects. UV radiation can induce nonmelanoma (basal cell carcinoma, squamous cell carcinoma) and melanoma skin cancer. ${ }^{12}$

The erythemogenic effect of UVB has been one of the main limitations to its use. The erythemogenic effect is lower with NB-UVB, although this technique was assumed to have a $50 \%$ higher risk of carcinogenesis (although this can be reduced by less exposure). ${ }^{81}$ In 2005, Man et al reported a twofold increased risk of basal cell carcinoma after 4 years of follow-up in a cohort of 1,908 patients treated with phototherapy, but no increased risk of squamous cell carcinoma or melanoma. ${ }^{82}$ Osmancevic et al recently reported their large cohort study in 162 adult patients with psoriasis who had received more than 100 UVB treatments. The 5-year follow-up data were quite reassuring, in that only $4.9 \%$ of patients had developed skin cancer. The risk was higher in patients who had received a greater number of treatments, but was not considered related to the type of UVB lamp used. The risk of malignancy was comparable with that in the general population. ${ }^{83}$ Moreover, in 2008 , Hearn et al confirmed the absence of added carcinogenic risk in patients with psoriasis treated using NB-UVB $(n=3,867) .{ }^{84}$

UVA1 has a higher minimal erythema dose (assessed as $>130 \mathrm{~J} / \mathrm{cm}^{2}$ ) and causes sunburn less frequently than other forms of light therapy. However, UVA1 radiation is associated with acute dermal side effects and possibly long-term photodamage and carcinogenesis. ${ }^{40}$ The carcinogenic potential of NB-UVB, UVA, and especially UVA1 remains uncertain because of the controversial data, and further human studies are required to confirm the safety of these treatment modalities. $^{13,72,85,86}$

On the other hand, a carcinogenic effect was clearly identified in patients with psoriasis as a consequence of long-term use of PUVA. In a number of cohort studies, squamous cell carcinoma was diagnosed in more than half 
Table I Features of the main forms of phototherapy

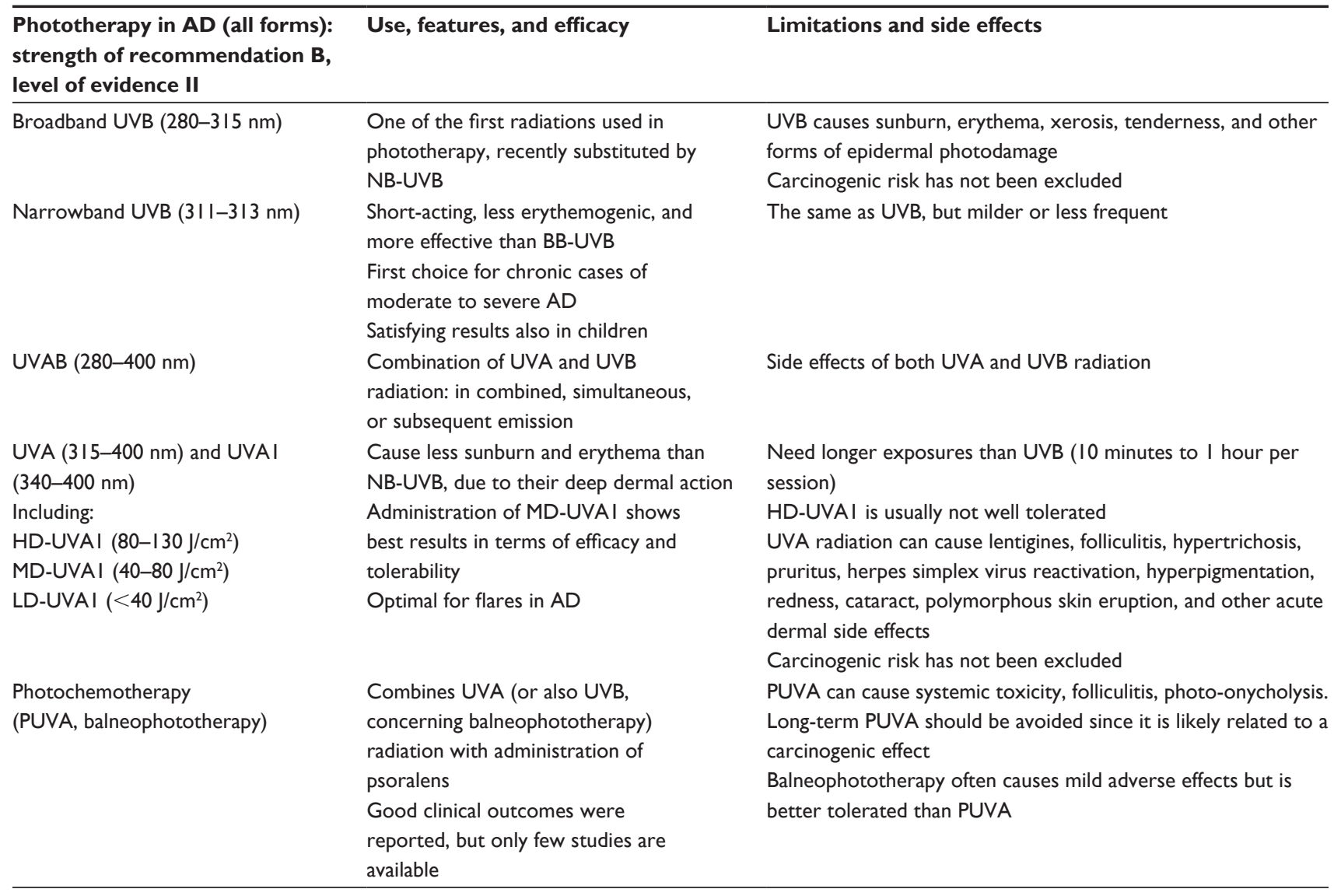

Abbreviations: UVA, ultraviolet $A ; A D$, atopic dermatitis; UVB, ultra violet $B ;$ UVAB, ultra violet $A B ;$ UVAI, ultra violet $A I ;$ LD, low dose; MD, medium dose; HD, high dose; PUVA, psoralen + UVA; BB, broad band; NB, narrow band.

of patients who had had more than 400 treatments during 25 years of follow-up, while one-third of the patients with more than 200 treatments developed basal cell carcinoma and an increased risk of melanoma was found in patients with more than 250 treatments. ${ }^{13,45,87-90}$

Systemic PUVA is also associated with short-term general toxicity, including nausea, vomiting, and hepatotoxicity, as well as longer-term photosensitivity and cataract. Choosing topical PUVA can lessen all these problems. ${ }^{13}$ Moreover, balneophototherapy has been reported to cause milder adverse reactions than NB-UVB, and is associated with better compliance and acceptance, along with a lower rate of withdrawal due to side effects. ${ }^{76}$

The applicability of phototherapy in pediatric patients has been investigated in numerous studies and is worthy of particular attention. Most trials confirm the tolerability and effectiveness of both UVA and UVB in children. ${ }^{31,51,53,56-60} \mathrm{In}$ a New Zealand study of the safety of NB-UVB radiation in 116 children with a variety of skin diseases reported by Tan et al, 36\% developed transient and minimally symptomatic erythema, but the overall tolerability was good in all the children. ${ }^{64}$ Moreover, involving the family in the decisionmaking process, together with reassuring children and making them feel comfortable with lamps and devices, can obtain good levels of compliance. However, the long-term risk of carcinogenesis in children with $\mathrm{AD}$ who have received phototherapy is still unclear, due to a lack of dedicated studies. It is known that long-term PUVA increases the incidence of non-melanoma skin cancers in children with psoriasis. ${ }^{50}$ For this reason, PUVA is commonly avoided in children, and NB-UVB is usually preferred. Phototherapy should be used with caution in children and reserved for refractory or severe cases. Because of the possible long-term risks, Ring et al suggest in their 2012 guidelines to avoid the use of phototherapy in children. ${ }^{21}$ Table 1 summarizes the features of the main modalities of phototherapy as illustrated in this review.

\section{Conclusion}

Phototherapy represents an optimal resource for the treatment of AD. Considered a second-line intervention, it should be reserved for patients who have not responded to environmental or topical measures. It can be used as a 
monotherapy or combined with systemic drugs, in particular corticosteroids, acting in synergy and reducing the doses needed. Light therapy includes a variety of techniques; UVA1, NB-UVB, and balneophototherapy in particular have gained importance in recent years. Phototherapy is effective for both acute (UVA1) and chronic (NB-UVB) cases of AD, both in adults and children. Its use is generally considered safe and it is well tolerated. However, some short-term and long-term adverse effects have been described, and a risk of carcinogenesis has not been excluded. Therefore, phototherapy must be used conscientiously, especially in children, and should take into account the patient's features and overall condition.

\section{Disclosure}

The authors report no conflicts of interest in this work.

\section{References}

1. Bieber T. Atopic dermatitis. Ann Dermatol. 2010;22:125-137.

2. Tintle S, Shemer A, Suárez-Fariñas M, et al. Reversal of atopic dermatitis with narrow-band UVB phototherapy and biomarkers for therapeutic response. J Allergy Clin Immunol. 2011;128:583-593. e1-e4.

3. Elias PM, Hatano Y, Williams ML, et al. Basis for the barrier abnormality in atopic dermatitis: outside-inside-outside pathogenic mechanisms. J Allergy Clin Immunol. 2008;121:1337-1343.

4. Lee HJ, Lee SH. Epidermal permeability barrier defects and barrier repair therapy in atopic dermatitis. Allergy Asthma Immunol Res. 2014;6:276-287.

5. Dainichi T, Hanakawa S, Kabashima K, et al. Classification of inflammatory skin diseases: a proposal based on the disorders of the three-layered defense systems, barrier, innate immunity and acquired immunity. J Dermatol Sci. 2014;76:81-89.

6. Guttman-Yassky E, Lowes MA, Fuentes-Duculan J, et al. Low expression of the IL-23/Th17 pathway in atopic dermatitis compared to psoriasis. J Immunol. 2008;181:7420-7427.

7. Leung YM, Guttman-Yassky E. Deciphering the complexities of atopic dermatitis: shifting paradigms in treatment approaches. J Allergy Clin Immunol. 2014;134:769-779.

8. Levy ML. Atopic dermatitis: understanding the disease and its management. Curr Med Res Opin. 2007;23:3091-3103.

9. Boguniewicz M, Leung DY. Recent insights into atopic dermatitis and implications for management of infectious complications. J Allergy Clin Immunol. 2010;125:4-13.

10. Eichenfield LF, Tom WL, Berger TG, et al. Guidelines of care for the management of atopic dermatitis: section 2. Management and treatment of atopic dermatitis with topical therapies. J Am Acad Dermatol. 2014;71:116-132.

11. Akdis CA, Akdis M, Bieber T, et al. Diagnosis and treatment of atopic dermatitis in children and adults: European Academy of Allergology and Clinical Immunology/American Academy of Allergy, Asthma and Immunology/PRACTALL Consensus Report. Allergy. 2006;61:969-987.

12. Sidbury R, Davis DM, Cohen DE, et al. Guidelines of care for the management of atopic dermatitis. J Am Acad Dermatol. 2014;71: 327-349.

13. Grundmann $\mathrm{SA}$, Beissert $\mathrm{S}$. Modern aspects of phototherapy for atopic dermatitis. J Allergy (Cairo). 2012;2012:121797.

14. Goeckerman W. Treatment of psoriasis. Northwest Med. 1925;24: 229-231.

15. Nexman PH. Clinical Studies of Besnier's Prurigo. Dissertation. Copenhagen, Denmark: Rosenkilde and Bagger; 1948.
16. Morison WL, Parrish J, Fitzpatrick TB. Oral psoralen photochemotherapy of atopic eczema. Br J Dermatol. 1978;98:25-30.

17. Gambichler T. Management of atopic dermatitis using photo(chemo) therapy. Arch Dermatol Res. 2009;301:197-203.

18. Majoie IM, Oldhoff JM, van Weelden H, et al. Narrowband ultraviolet $\mathrm{B}$ and medium-dose ultraviolet $\mathrm{A} 1$ are equally effective in the treatment of moderate to severe atopic dermatitis. JAm Acad Dermatol. 2009;60:77-84.

19. Garritsen FM, Brouwer MWD, Limpens J, Spuls PI. Photo(chemo) therapy in the management of atopic dermatitis: an updated systematic review with implications for practice and research. Br J Dermatol. 2014; 170:501-513.

20. Jekler J, Larkö O. Combined UVA-UVB versus UVB phototherapy for atopic dermatitis: a paired-comparison study. J Am Acad Dermatol. 1990;22:49-53.

21. Ring J, Alomar A, Bieber T, et al. Guidelines for treatment of atopic eczema (atopic dermatitis) Part II. J Eur Acad Dermatol Venereol. 2012;26:1176-1193.

22. Godar DE. UVA1 radiation triggers two different final apoptotic pathways. J Invest Dermatol. 1999;112:3-12.

23. Gambichler T, Skrygan M, Tomi NS, Altmeyer P, Kreuter A. Changes of antimicrobial peptide mRNA expression in atopic eczema following phototherapy. Br J Dermatol. 2006;155:1275-1278.

24. Ozawa M, Ferenczi K, Kikuchi T, et al. 312-nanometer ultraviolet B light (narrow-band UVB) induces apoptosis of T cells within psoriatic lesions. J Exp Med. 1999;189:711-718.

25. Meduri NB, Vandergriff T, Rasmussen H, Jacobe H. Phototherapy in the management of atopic dermatitis: a systematic review. Photodermatol Photoimmunol Photomed. 2007;23:106-112.

26. Scheinfeld NS, Tutrone WD, Weinberg JM, et al. Phototherapy of atopic dermatitis. Clin Dermatol. 2003;24:2-6.

27. Byun HJ, Lee HI, Kim B, et al. Full-spectrum light phototherapy for atopic dermatitis. Int J Dermatol. 2011;50:94-101.

28. Dennis M, Bhutani T, Koo J, et al. Goeckerman therapy for the treatment of eczema: a practical guide and review of efficacy. J Dermatolog Treat. 2013;24:2-6.

29. Jekler J, Larkö O. Phototherapy for atopic dermatitis with ultraviolet A (UVA), low-dose UVB and combined UVA and UVB: two pairedcomparison studies. Photodermatol Photoimmunol Photomed. 1991;8: 151-156.

30. Jekler J, Larkö O. UVA solarium versus UVB phototherapy of atopic dermatitis: a paired-comparison study. Br J Dermatol. 1991;125: 569-572.

31. Jekler J, Larkö O. UVB phototherapy of atopic dermatitis. Br J Dermatol. 1988;119:697-705.

32. Hannuksela M, Karvonen J, Husa M, Jokela R, Katajamäki L, Leppisaari M. Ultraviolet light therapy in atopic dermatitis. Acta Derm Venereol Suppl (Stockh). 1985;114:137-139.

33. van Weelden H, De La Faille HB, Young E, van der Leun JC. A new development in UVB phototherapy of psoriasis. Br J Dermatol. 1988;119:11-19.

34. Morita A, Werfel T, Stege H, et al. Evidence that singlet oxygen-induced human $\mathrm{T}$ helper cell apoptosis is the basic mechanism of ultraviolet-A radiation phototherapy. J Exp Med. 1997;186:1763-1768.

35. Breuckmann F, von Kobyletzki G, Avermaete A, et al. Mononuclear cells in atopic dermatitis in vivo: immunomodulation of the cutaneous infiltrate by medium-dose UVA1 phototherapy. Eur J Med Res. 2002;7:315-322.

36. Plettenberg H, Stege H, Megahed M, et al. Ultraviolet A1 (340-400 nm) phototherapy for cutaneous T-cell lymphoma. J Am Acad Dermatol. 1999;41:47-50.

37. Breuckmann F, von Kobyletzki G, Avermaete A, Kreuter A, Altmeyer P. Efficacy of ultraviolet A1 phototherapy on the expression of bcl-2 in atopic dermatitis and cutaneous T-cell lymphoma in vivo: a comparison study. Photodermatol Photoimmunol Photomed. 2002;18:217-222.

38. Breuckmann F, Pieck C, Kreuter A, et al. Opposing effects of UVA1 phototherapy on the expression of bcl-2 and p53 in atopic dermatitis. Arch Dermatol Res. 2001;293:178-183. 
39. Beissert S, Granstein RD. UV-induced cutaneous photobiology. Crit Rev Biochem Mol Biol. 1996;31:381-404.

40. Zandi S, Kalia S, Lui H. UVA1 phototherapy: a concise and practical review. Skin Therapy Lett. 2012;17:1-4.

41. Darsow U, Wollenberg A, Simon D, et al. ETFAD/EADV Eczema Task Force 2009 position paper on diagnosis and treatment of atopic dermatitis. J Eur Acad Dermatol Venereol. 2010;24:317-328.

42. Legat FJ, Hofer A, Brabek E, Quehenberger F, Kerl H, Wolf P. Narrowband UV-B vs medium-dose UV-A1 phototherapy in chronic atopic dermatitis. Arch Dermatol. 2003;139:223-224.

43. Fitzpatrick TB, Pathak MA. Research and development of oral psoralen and longwave radiation photochemotherapy: 2000 BC-1982 AD. Natl Cancer Inst Monogr. 1984;66:3-11.

44. Stege H, Berneburg M, Ruzicka T, Krutmann J. [Cream PUVA photochemotherapy]. Hautarzt. 1997;48:89-93. German.

45. Lim JL, Stern RS. High levels of ultraviolet B exposure increase the risk of non-melanoma skin cancer in psoralen and ultraviolet A-treated patients. J Invest Dermatol. 2005;124:505-513.

46. Marks DI, Fox RM. Mechanisms of photochemotherapy-induced apoptotic cell death in lymphoid cells. Biochem Cell Biol. 1991;69: 754-760.

47. Johnson R, Staiano-Coico L, Austin L, Cardinale I, Nabeya-Tsukifuji R, Krueger JG. PUVA treatment selectively induces a cell cycle block and subsequent apoptosis in human T-lymphocytes. Photochem Photobiol. 1996;63:566-571.

48. Institute for Quality and Efficiency in Health Care. Balneophototherapy. 2004 IQWiG Reports - Commission No N04-04. Available from: http://www.ncbi.nlm.nih.gov/pubmedhealth/PMH0034017/. Accessed June 20, 2015.

49. Tominaga M, Tengara S, Kamo A, Ogawa H, Takamori K. Psoralen-ultraviolet A therapy alters epidermal Sema3A and NGF levels and modulates epidermal innervation in atopic dermatitis. $J$ Dermatol Sci. 2009;55:40-46.

50. Menter A, Korman NJ, Elmets CA, et al. Guidelines of care for the management of psoriasis and psoriatic arthritis: Section 5. Guidelines of care for the treatment of psoriasis with phototherapy and photochemotherapy. J Am Acad Dermatol. 2010;62:114-135.

51. Tay YK, Morelli JG, Weston WL. Experience with UVB phototherapy in children. Pediatr Dermatol. 1996;13:406-409.

52. Grundmann-Kollmann M, Behrens S, Podda M, Peter RU, Kaufmann R, Kerscher M. Phototherapy for atopic eczema with narrow-band UVB. J Am Acad Dermatol. 1999;40(6 Pt 1):995-997.

53. Clayton TH, Clark SM, Turner D, Goulden V. The treatment of severe atopic dermatitis in childhood with narrowband ultraviolet B phototherapy. Clin Exp Dermatol. 2007;32:28-33.

54. Rombold S, Lobisch K, Katzer K, Grazziotin TC, Ring J, Eberlein B. Efficacy of UVA1 phototherapy in 230 patients with various skin diseases. Photodermatol Photoimmunol Photomed. 2008;24:19-23.

55. Morison WL, Baughman RD, Day RM, et al. Consensus workshop on the toxic effects of long-term PUVA therapy. Arch Dermatol. 1998;134: 595-598.

56. Uetsu N, Horio T. Treatment of persistent severe atopic dermatitis in 113 Japanese patients with oral psoralen photo-chemotherapy. J Dermatol. 2003;30:450-457.

57. Yoshiike T, Aikawa Y, Sindhvananda J, Ogawa H. A proposed guideline for psoralen photochemotherapy (PUVA) with atopic dermatitis: successful therapeutic effect on severe and intractable cases. $J$ Dermatol Sci. 1993;5:50-53.

58. Atherton DJ, Carabott F, Glover MT, Hawk JL. The role of psoralen photochemotherapy (PUVA) in the treatment of severe atopic eczema in adolescents. Br J Dermatol. 1988;118:791-795.

59. Jury CS, McHenry P, Burden AD, Lever R, Bisland D. Narrowband ultraviolet B (UVB) phototherapy in children. Clin Exp Dermatol. 2006;31: 196-199.

60. Tzung TY, Lin CB, Chen YH, Yang CY. Pimecrolimus and narrowband UVB as monotherapy or combination therapy in children and adolescents with atopic dermatitis. Acta Derm Venereol. 2006;86:34-38.
61. Koek MB, Sigurdsson V, van Weelden H, Steegmans PH, BruijnzeelKoomen CA, Buskens E. Cost effectiveness of home ultraviolet B phototherapy for psoriasis: economic evaluation of a randomised controlled trial (PLUTO study). BJM. 2010;340:c1490.

62. Cameron H, Yule S, Dawe RS, Ibbotson SH, Moseley H, Ferguson J. Review of an established UK home phototherapy service 1998-2011: improving access to a cost-effective treatment for chronic skin disease. Public Health. 2014;128:317-324.

63. George SA, Bilsland DJ, Johnson BE, Ferguson J. Narrow-band (TL-01) UVB air-conditioned phototherapy for chronic severe adult atopic dermatitis. Br J Dermatol. 1993;128:49-56.

64. Tan E, Lim D, Rademaker M. Narrowband UVB phototherapy in children: a New Zealand experience. Australas J Dermatol. 2010;51: 268-273.

65. Darné S, Leech SN, Taylor AE. Narrowband ultraviolet B phototherapy in children with moderate-to-severe eczema: a comparative cohort study. Br J Dermatol. 2014;170:150-156.

66. Krutmann J, Diepgen TL, Luger TA, et al. High-dose UVA1 therapy for atopic dermatitis: results of a multicenter trial. JAm Acad Dermatol. 1998;38:589-593.

67. Krutmann J, Czech W, Diepgen T, Niedner R, Kapp A, Schöpf E. High-dose UVA1 therapy in the treatment of patients with atopic dermatitis. J Am Acad Dermatol. 1992;26(2 Pt 1):225-230.

68. von Kobyletzki G, Pieck C, Hoffmann K, Freitag M, Altmeyer P. Medium-dose UVA1 cold-light phototherapy in the treatment of severe atopic dermatitis. J Am Acad Dermatol. 1999;41:931-937.

69. Dittmar HC, Pflieger D, Schöpf E, Simon JC. [UVA1 phototherapy. Pilot study of dose finding in acute exacerbated atopic dermatitis]. Hautartz. 2001;52:423-427. German.

70. Reynolds NJ, Franklin V, Gray JC, Diffey BL, Farr PM. Narrow-band ultraviolet $\mathrm{B}$ and broad-band ultraviolet A phototherapy in adult atopic eczema: a randomised controlled trial. Lancet. 2001;357:2012-2016.

71. Abeck D, Schmidt T, Fesq H, et al. Long-term efficacy of medium-dose UVA1 phototherapy in atopic dermatitis. J Am Acad Dermatol. 2000; 42(2 Pt 1):254-257.

72. Tzaneva S, Seeber A, Schwaiger M, Hönigsmann H, Tanew A. Highdose versus medium dose UVA1 phototherapy for patients with severe generalized atopic dermatitis. J Am Acad Dermatol. 2001;45:503-507.

73. Gambichler T, Othlinghaus N, Tomi NS, et al. Medium-dose ultraviolet (UV) A1 vs narrowband UVB phototherapy in atopic eczema: a randomized crossover study. Br J Dermatol. 2009;160:652-658.

74. Tzaneva S, Kittler H, Holzer G, et al. 5-Methoxypsoralen plus ultraviolet (UV) A is superior to medium-dose UVA1 in the treatment of severe atopic dermatitis: a randomized crossover trial. Br J Dermatol. 2010;162:655-660.

75. Der-Petrossian M, Seeber A, Hönigsmann H, Tanew A. Half-side comparison study on the efficacy of 8-methoxypsoralen bath-PUVA versus narrow-band ultraviolet B phototherapy in patients with severe chronic atopic dermatitis. Br J Dermatol. 2000;142:39-43.

76. Heinlin J, Schiffner-Rohe J, Schiffner R, et al. A first prospective randomized controlled trial on the efficacy and safety of synchronous balneophototherapy vs narrow-band UVB monotherapy for atopic dermatitis. J Eur Acad Dermatol Venereol. 2011;25:765-773.

77. Granlund H, Erkko P, Remitz A, et al. Comparison of cyclosporin and UVAB phototherapy for intermittent one-year treatment of atopic dermatitis. Acta Derm Venereol. 2001;81:22-27.

78. Pasić A, Ceović R, Lipozencić J, et al. Phototherapy in pediatric patients. Pediatr Dermatol. 2003;20:71-77.

79. Medicis. Prescribing information (pimecrolimus). Available from: http:// elidel-us.com

80. Astellas. Medication guide (tacrolimus). Available from: http:// www.protopic.com/pdf/protopic_med_guide.pdf. Accessed June 19, 2015.

81. Kirke SM, Lowder S, Lloyd JJ, Diffey BL, Matthews JN, Farr PM. A randomized comparison of selective broadband UVB and narrowband UVB in the treatment of psoriasis. J Invest Dermatol. 2007;127: 1641-1646. 
82. Man I, Crombie IK, Dawe RS, Ibbotson SH, Ferguson J. The photocarcinogenic risk of narrowband UVB (TL-01) phototherapy: early follow-up data. Br J Dermatol. 2005;152:755-757.

83. Osmancevic A, Gillstedt M, Wennberg AM, Larkö O. The risk of skin cancer in psoriasis patients treated with UVB therapy. Acta Derm Venereol. 2014;94:425-430.

84. Hearn RM, Kerr AC, Rahlm KF, Ferguson J, Dawe RS. Incidence of skin cancers in 3867 patients treated with narrow-band ultraviolet B phototherapy. Br J Dermatol. 2008;159:931-935.

85. Lee E, Koo J, Berger T. UVB phototherapy and skin cancer risk: a review of the literature. Int J Dermatol. 2005;44:355-360.

86. von Thaler AK, Kamenisch Y, Berneburg M. The role of ultraviolet radiation in melanomagenesis. Exp Dermatol. 2010;19: $81-88$.
87. Nijsten TE, Stern RS. The increased risk of skin cancer is persistent after discontinuation of psoralen + ultraviolet A: a cohort study. J Invest Dermatol. 2003;121:252-258.

88. Stern RS, Liebman EJ, Väkevä L. Oral psoralen and ultraviolet-A light (PUVA) treatment of psoriasis and persistent risk of nonmelanoma skin cancer. PUVA Follow-up Study. J Natl Cancer Inst. 1998;90: 1278-1284.

89. Stern RS; PUVA Follow up Study. The risk of melanoma in association with long-term exposure to PUVA. J Am Acad Dermatol. 2001;44: $755-761$.

90. Stern RS, Nichols KT, Väkevä L. Malignant melanoma in patients treated for psoriasis with methoxsalen (psoralen) and ultraviolet A radiation (PUVA). The PUVA Follow-Up Study. N Engl J Med. 1997;336: 1041-1045.

\section{Publish your work in this journal}

Clinical, Cosmetic and Investigational Dermatology is an international, peer-reviewed, open access, online journal that focuses on the latest clinical and experimental research in all aspects of skin disease and cosmetic interventions. All areas of dermatology will be covered; contributions will be welcomed from all clinicians and basic science researchers globally. This journal is indexed on CAS. The manuscript management system is completely online and includes a very quick and fair peer-review system, which is all easy to use. Visit http://www.dovepress.com/testimonials.php to read real quotes from published authors. 